\title{
The Analysis of the Factors Affecting the Implementation of Virtual R\&D in Iranian Tile and Ceramic Companies Using Structural Equation Modeling Approach
}

https://doi.org/10.21272/sec.3(4).86-96.2019.

\author{
Abolfazl Akhondzadeh, ORCID: https://orcid.org/0000-0001-8160-3425 \\ Master of Science, PhD Candidate, Researcher, Yazd University of Science and Art, Iran
}

\begin{abstract}
The final goal of this study is to provide a model with structural modeling approach of virtual R \& D implementation in Iranian ceramic tile companies and small and medium-sized industries and services are one of the broadest fields of activity of manufacturing and economic enterprises that are of great importance. Accordingly, the establishment and expansion of research and development systems in order to infuse new sciences and technologies into this industry is of great importance. Over the past few decades, in a highly competitive market, the development of new products has long been considered as a major contributing factor to the survival and growth of SMEs and manufacturing units and economic enterprises have a great desire to create and develop R \& D and investment systems for their efficiency so the necessity of conducting this research was created for Iranian companies because SMEs are considered as engines of economic growth, particularly in developing countries and in a day-to-day market for freedom, the survival and continuity of SMEs depend on their ability to enhance their performance and production that are in accordance with international standards. The questionnaires and interviews used to examine the research questions. It was distributed among 114 experts after ensuring the reliability and validity. The research strategy is a surveycorrelation questionnaire that has been compiled by a researcher-made questionnaire. The results of this study showed that the technology structure in virtual teams does not directly affect the implementation of virtual $\mathrm{R}$ $\& \mathrm{D}$. The knowledge structure of the individuals and the process structure can have a direct effect on the implementation of virtual R \& D in the other hand this paper acknowledges the progress made over the past several decades, it focuses on the challenges and limits of Iranian Tile and Ceramic Companies.
\end{abstract}

Keywords: virtual research and development, small and medium-sized industries, interpretive structural modeling, virtual teams.

JEL Classification: 032, 033, 021, L69.

Cite as: Abolfazl Akhondzadeh (2019). The Analysis of the Factors Affecting the Implementation of Virtual R\&D in Iranian Tile and Ceramic Companies Using Structural Equation Modeling Approach. SocioEconomic Challenges, 3(4), 86-94. https://doi.org/10.21272/sec.3(4).86-94.2019.

(C) The Author, 2019. This article is published with open access at Sumy State University.

\section{Introduction}

Today, R \& D systems play an effective role in creating and developing knowledge and technology, reforming processes and practices, providing new opportunities for entrepreneurship and business development, and thus improving the economic growth situation in manufacturing firms. (Rust, 2015). Therefore, manufacturing units and economic enterprises have a great desire to create and develop R \& D and investment systems for their efficiency. These types of investments lead to the formation of emerging or adapted technologies, and ultimately the development of businesses and the formation of new businesses. (Stam, 2009) The main function of research and development systems is to identify and solve the problems of manufacturing units by utilizing scientific research and problem-solving processes as well as entering into new science and technology for the efficiency of the manufacturing processes. Based on this, R \& D systems can play an effective role in promoting economic indicators and organizational productivity.

In today's world, small and medium-sized industries and services are one of the broadest fields of activity of manufacturing and economic enterprises that are of great importance. Accordingly, the establishment and expansion of research and development systems in order to infuse new sciences and technologies into this 
industry is of great importance. Small and medium-sized enterprises (SMEs) play a vital role in employment, rapid development of new products and the growth of an economic system (AleEbrahim et al., 2010) SMEs are considered as engines of economic growth, particularly in developing countries. (Singh et al., 2008; Radas \& bozik, 2009) In a day-to-day market for freedom, the survival and continuity of SMEs depend on their ability to enhance their performance and production that are in accordance with international standards (Gomez \& Simpson, 2007)

Over the past few decades, in a highly competitive market, the development of new products has long been considered as a major contributing factor to the survival and growth of SMEs (AleEbrahim et al., 2009). To compete globally and to overcome rapid technological change in the incredible variety of product manufacturing, SMEs must be able to synchronize with product innovation (Laforet, 2008). One of the most important requirements is to enable SMEs to update their knowledge and to work with spaces and collaborative networks to increase capacity. Their innovation brings this knowledge into service (Flores, 2006) As one of the important aspects of networking is to maximize the benefits that can be gained through the participation of beneficiaries in profit and loss. It is important for companies to collaborate in networks so that capabilities, capacities and abilities are bilaterally developed to products new services and complete systems. (Chen et al., 2008)

On the other hand, rapid changes in the business environment tend to be organized in an organization that has high flexibility and portability, so that the market can deliver new products. Virtual teams can help in addressing these issues. (AleEbrahim et al., 2009) In recent years, R \& D teams have gone very virtual, and now it is up to the teams to do their R \& D assignments (Leenders \& Engelen, 2006; Huang, 2009) Virtual R $\& \mathrm{D}$ teams can be a means to increase the efficiency and competitiveness of SMEs in local (domestic) and global markets (AleEbrahim et al., 2010).

Teams have become the main component for the survival of companies (Lurey \& Raisinghani, 2010). The main advantage of using a geographically dispersed R \& D network structure is the ability to communicate with the center selectively and selectively in order to reduce costs and extend the continuity of the final system and increasing the lifespan of the product development cycle, many organizations have gone a long way from linear collaboration, and have been moving towards symmetrical collaborations through collaborative project/production teams. (Bochenek, 2004; Criscuolo., 2005) Virtual R \& D teams can be critical choices for active reinforcement and facilitation of SMEs activities. (AleEbrahim et al., 2010).

Accordingly, the present study describes the nature and function of research and development systems and explains the factors influencing their success and aims to achieve a more correct understanding of the factors affecting the development of research and development systems in small and medium enterprises. Referring to the results of a survey work, the effect of intra-organizational factors on the success of research and development activities in this section are discussed.

\section{Literature review}

\section{Research and Development (R \& D)}

Research and Development According to the OECD Institute ${ }^{1}$, which consists of the 30 advanced countries in the world means the constructive activities of a systematic foundation aimed at enhancing human knowledge and social culture and utilizing this knowledge in new applications. Today, the expansion and design of new products is becoming more and more a major factor for companies.

In today's industry, which is changing rapidly, stagnation will be the death of a company, and this requirement is due to the constant changes in technology, the existence of competitors, and the prioritization of customer demand. Research and development, apart from its definite affiliation with technical and scientific development, also has a special economic meaning. Today, in many countries in the world, investment in $\mathrm{R}$ \& D reflects an organizational or governmental move to go beyond current profitability and improve performance and returns in the future.

According to a 2006 report, four of the world's largest investors for the R \& D sector were the United States with 343 billion, the European Union with 231 billion, Japan with 130 billion, and China with 115 billion

\footnotetext{
${ }^{1}$ Organization for Economic Co-operation and Development.
} 
dollars. What is certain is that $\mathrm{R} \& \mathrm{D}$ activities should be guided by the direction of the organization or companies and universities with government investment. In the field of commerce, $\mathrm{R} \& \mathrm{D}$ also means moving to a bright future and long-term activities in science and technology using scientific research (Movahedi, 2013).

\section{Definition of Small and Medium Industries}

According to the Ministry of Industries and Mines and the Ministry of Agricultural Jihad, small and medium enterprises have industrial and service units (urban and rural) with fewer than 50 workers. (Unido., 2003). The Ministry of Cooperative also uses the definitions of the Ministry of Industries and Mines and Iran's Statistics Center on these industries. The Center for Statistics of Iran classified businesses into four groups: businesses with 1 to 9 workers, 10-49 workers, 50 to 99 workers and more than 100 workers. (Statistics of 1989) Although this classification is apparently similar to the EU definitions, the Iranian Center of Statistics only considers businesses less than 10 workers as small and medium enterprises and considers other businesses "large industrial plants". The Central Bank of Iran also sees businesses below 100 in the labor force as small and medium enterprises.

\section{Modeling of Structural Equations}

Structural Equation Modeling is a very general and powerful multivariate analysis technique from the family of multivariate regression and, more precisely, the extension of the general linear model, which allows the researcher to test a set of regression equations simultaneously. Structural equation modeling is a comprehensive approach for testing hypotheses about the relationships between observed and hidden variables, sometimes called structural analysis of covariance, causal modeling, and sometimes also Lisrel, but the prevailing term in these days is the structural equation modeling or summation of the SEM (Hooman, 2005).

\section{Virtual Research and Development}

Small and medium-sized enterprises (SMEs) play a vital role in terms of employment, rapid development of new products and economic growth in the economy. They are considered as engines of economic growth, especially in developing countries (Ale Ebrahim et al., 2010; Radas \& Bozik, 2009). The survival of SMEs depends on their ability to improve the performance and production of goods that can apply international standards in an open market environment. (Gomez \& Simpson, 2007) Over the past few decades, the development of new products has increasingly become an important factor in competitive market conditions, it is known to ensure the survival and growth of SMEs (AleEbrahim et al., 2009).

To compete globally and to overcome rapid technological changes in the mass production of a variety of products, SMEs need to be innovated. (Laforet, 2008). An important requirement is that MVSs should develop new knowledge to develop their own innovation capabilities through their environments and shared networks in their development (Flores, 2006). Since an important aspect of networking is the optimization of the benefits that can by sharing the risks and benefits with the participants, networking is important in order to develop the capacity, ability and competency of companies to develop new products and provide complementary systems for companies. (Kang, Tong, 2008). On the other hand, rapid changes in the business environment tend to design highly flexible and agile organizations to market new products (Palacios, 2002). Virtual teams can respond to these issues. (AleEbrahim et al., 2009). In recent years, R \& D teams have increasingly become virtualized and are currently affiliated with teams for their research and development tasks (AleEbrahim et al., 2010; Leenders, 2006). R \& D teams can be a tool for increasing the efficiency and competitiveness of SMEs in local and global markets (AleEbrahim et al., 2010). Such teams are essential to rescue companies (Lurey, 2001). The main advantage of implementing a research network structure and geographically dispersed development is the ability to choose the center of excellence. (Criscuolo, 2005). To reduce costs and extend the whole cycle of system and product development, many organizations work through integrated project / product teams. (Bochenek, 2004). Virtual research and development teams can be an appropriate tool for maintaining and facilitating SME operations (AleEbrahim et al., 2010). However, any company cannot overcome the requirements of the market gradually or immediately due to dynamic knowledge in a competitive environment. Increasing competition and reducing product life cycles will accelerate the pressure on companies to develop new products. In response to these urgent needs, new methods must be adapted to flexible conditions (May.A et al., 2001). With the rapid expansion of the media and electronic communications over the past decades, distributed works have become much easier, faster and more efficient. (Hertel, 2005) IT provides the infrastructure necessary to support the development of new organizational forms. 
(AleEbrahim, N., Abdul Rashid, S. H., Ahmed, S. \& Taha, Z., 2011). Virtual teams constitute an organizational form, one of which can transform the workplace and provide organizations with an unprecedented level of flexibility and accountability. (Paul et al., 2005) Virtual network structure to improve communication and coordination and encourage mutual sharing of inter-institutional resources and competencies is used (Chen et al., 2008). Therefore, it seems to be appropriate to create and manage creativity in new product development teams. (Leenders, 2003). Although Wagner and Holger (2006) in a research paper titled Insights for R \& D and project managers showed that joint product development, provides benefits for both managers from the buyer as well as the client, but little research has been done on the effective factors and the effect of virtual research and development teams in SMEs. Research on virtual teams is still in its infancy. (Arnett, 2015). Therefore, the launch of an infrastructure for virtual teams still requires major engineering efforts that are a major obstacle to the implementation of this new paradigm (Afsarmanesh et al., 2003). Effective and efficient collaboration between disciplines and distributed teams for the success of projects Engineering is essential. (Shin., 2005). Therefore, experts believe that more research is needed to explore ways to increase the performance of virtual teams. (El-tayeh et al., 2008) Virtual teams by communicating and participating with local actors effectively deal with cultural issues such as the design and introduction of new products for specific markets (Amant, 2008).

\section{Teams and Virtual Teams}

The word "teams" was used in the United States in the early 1960s. In the late 1980s and early 1990s, many companies used autonomous or employee teams. To reduce bureaucracy, reduce cycle times and improve service, line-level employees engage with decision-making responsibilities and resolve related issues traditionally associated with management. By the mid-1990s, many companies, such as Goodyear, Motorola, Texas Instruments, and General Electric, transferred the concept of the team to their affiliated companies in Asia, Europe, and Latin America to link global human resource work (Kirkman et al., 2010). Nowadays, with the advent of communication technology and globalization, virtual teams have grown rapidly around the world. In this era, there is growing popularity for the structure of the virtual team in the organization. Martinez et al. (2004) We know where we are going and where? In a major study of literature on virtual teams, "with the exception of rare, all organizational teams are somewhat virtual." This action is apart working from the workplace around the world.

\section{Research Background}

Shahabadi (2010) investigated the role of research and development on the productivity of the industrial sector in Iran. The present study evaluates the theoretical and analytical aspects of the role of accumulation of domestic R\&D capital, human capital, as well as the role of accumulation of foreign capital R \& D (through the transfer of crystallized technology in the importation of intermediate-capital goods) on the growth of total factor productivity of the industrial sector of the Iranian economy. Since the research and development activities of the Iranian industrial sector are insignificant in comparison with developed countries, the Iranian economy, like other developing countries, could hope for the role of the accumulation of foreign research and development and its overflows on the growth of total productivity of the production factors of this sector. Because absorption of foreign research and development spurts along with the development of domestic R \& $\mathrm{D}$ activities provides a more favorable context for increasing the total productivity of production factors.

Therefore, in this study, the effect of direct accumulation of domestic and foreign R \& D capital (the crystallized technology in the importation of intermediate-capital goods) and human capital on the growth of total factor productivity of the industrial sector of Iran during the 1947-2006 has been studied. The results of the analysis indicate that human capital and accumulation of foreign capital R \& D have the most positive effect on the growth of total factor productivity of the industrial sector.

In a study by Hosseini Nia et al. (2015), the factors affecting the success of virtual research and development in the food industry, R \& D systems played an effective role in creating knowledge and technology, the emergence of innovative ideas and ideas, the reconstruction of processes and working practices and providing new opportunities for entrepreneurship and business development. Accordingly, there is a strong tendency towards creating and developing research and development systems in the economic and manufacturing enterprises. This issue has also been concerned in the food industry, and the research and development unit has been created as one of the most effective parts of the production process in most of the large food industry 
units. Based on research, the success of research and development systems requires the existence of some infrastructures and the availability of a set of internal and external factors.

In this article, we examine the nature and functions of research and development systems and explain the factors and conditions affecting the efficiency of these systems. The study examines the effect of organizational components on the success of research and development systems in food industry units of the country. In this research, in order to investigate the status of organizational components in research and development systems, the views of a group of managers of research and development units in the small and medium enterprises of Iran have been studied. Based on the views of managers, human factors, conditions related to the status of organizational structure and how organizational processes have a significant effect on the success of research and development systems in food industry enterprises. Based on this, suggestions are made to improve the status of these factors in order to achieve a higher level of effectiveness in research and development systems.

The effect of the success of virtual research and development systems on the factors within the organization in the study of Modarres et al. (2006) has also been noted. In this study, we introduce the organization's characteristics of mother organization and product strategy as two important factors in organizing research and development teams.

In a study by Ebrahim al-Ahmad and Taha, titled R \& D and New Product Development (2010), they concluded that in order to reduce costs and extend the continuity of the final system and extend the lifecycle of product development, many organizations were far from the linear co-operation and has moved towards symmetrical collaboration using integrated project / production teams with cross-functions. Virtual R \& D teams can be critical choices for strengthening and facilitating SME activities.

In Hertler et al. (2005), which explores the management of virtual teams, it has been shown that, given the rapid growth of information in the field of electronics and communication media over the past decades, distribution and division of labor has become much easier, faster and more efficient. IT provides the foundation needed to develop new organizational forms.

Powell and Iowes (2004) conducted a study on virtual teams. The study concluded that virtual teams represent one of these organizational forms, one that can revolutionize the workplace and create organizations with levels of flexibility and efficiency. A virtual network structure is used to improve communication and coordination and to strengthen the interchange of resources and inter-organizational capabilities. Linders et al., In a study of being virtual, communication and new creativity in virtual networks (2003), showed that being virtual in the development and management of creativity in the development teams of new products and services is beneficial. Wagner and Hagel (2006), in a study of importing suppliers in product development, showed that the development of collaborative products benefits both managers as well as the business enterprise, few studies have been done on the influential factors and effects of virtual R \& D teams in SMEs.

\section{Conceptual Model of Research}

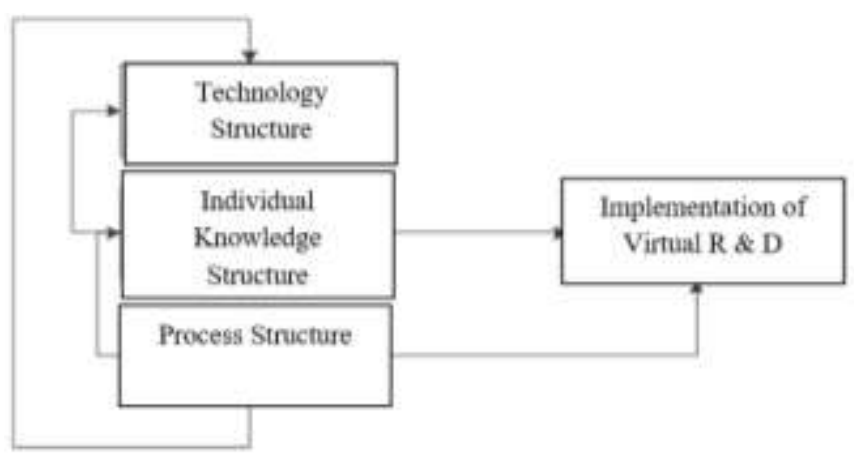

Figure 1. Conceptual Model of Research

Source: based on the research findings.

The research hypotheses are as follows: 
Hypothesis 1: The technology structure in virtual teams has a positive effect on virtual implementation of $\mathrm{R}$ \& D.

Hypothesis 2: The knowledge structure of individuals in virtual teams has a positive effect on virtual R \& D implementation.

Hypothesis 3: The process structure in virtual teams has a positive effect on virtual implementation of R \& D.

\section{Method}

The methodology of this study is survey-correlation in term of nature of the subject and the objectives and has been done in 2017.

The data needed for this study was gathered through a questionnaire and interviews with experts. After ensuring the reliability and validity of this questionnaire, it was distributed among 150 experts. In order to investigate the validity of the questionnaire, a researcher-made questionnaire was prepared in the first step, and its questions were drawn up based on expert opinions and research literature. After observation and careful examination by the professors, the guidance and counselor of the indeterminate and incomprehensible phrases was localized. In the second step, after eliminating the existing defects and shortcomings, four questionnaires were submitted to the faculty members of the management group to determine the validity of the questionnaires in order to determine the appropriateness of the questionnaires. After the calculations, the validity of the questionnaires was confirmed. In order to calculate the reliability of the data gathering tool, a sample of 50 people completed the questionnaire. In this method, to calculate the internal coordination of each questionnaire, its coefficient is calculated.

Table 1. Cronbach Alpha Coefficient

\begin{tabular}{|c|c|c|}
\hline Cronbach Alpha & No. Items & Technology Structure \\
\hline 0.7 & 5 & Individual Knowledge Structure \\
\hline 0.7 & 9 & Process Structure \\
\hline 0.65 & 6 & Implementation of R \& D \\
\hline 0.723 & 3 & Total \\
\hline 0.727 & 23 & \\
\hline
\end{tabular}

Source: based on the research findings.

The reliability of the questionnaire items has shown that the consistency statements of each section have a high correlation. The alpha value of above 0.7 represents a very good reliability of the questionnaire and the process structure terms are 0.65, which confirms the reliability relatively. (Bagozzi and Yi, 1988)

Regarding the research purpose, the statistical population of this research consisted of all managers of active units in the small and medium industries of Yazd province (about 200 people).

\section{Findings}

The research findings are two parts. The first part contains the descriptive findings of the research and the second part deals with the explanation and analysis of the data. In statistical analysis, SPSS and AMOS software tests have been used to check the accuracy of the results.

According to the information obtained through the software, $89.2 \%$ of the respondents are male and $10.8 \%$ are women. Also, $95.2 \%$ of the respondents are married and $4.8 \%$ are single people. $32.4 \%$ of the respondents were $26-35$ years old and $45.5 \%$ were $36-45$ years old and eventually $22.1 \%$ were between 46 and 55 years old and the results indicated that $64.2 \%$ of the respondents had BA degree and $34.5 \%$ had MA degree and $1.4 \%$ had PhD degrees.

To use parametric methods in data analysis, data needs to follow a normal distribution. For this purpose, Kolmogorov-Smirnov test is used to check the normal variables. In this test, the null hypothesis is considered normal and assumes that the variable is not normal. A significant value of more than 0.05 confirms the null hypothesis and confirms the normality of the variable.

$H_{\circ}$ : The data follows the normal distribution.

$H_{1}$ : Data does not follow the normal distribution. 
Therefore, according to Table (2), all variables are normal. As a result, parametric methods (t-test, Pearson correlation and structural equations) are used for comparative tests.

To investigate the relationship between the factors affecting virtual R \& D implementation, we use the Pearson correlation method. In this method, the following test is considered.

$$
\begin{aligned}
& H_{\circ}: \rho=0 \\
& H_{1}: \rho \neq 0
\end{aligned}
$$

Table 2. Normality of Variables

\begin{tabular}{|c|c|c|c|c|}
\hline Implementation of R \& D & Process Structure & Individual Knowledge Structure & Technology Structure & \\
\hline 0.831 & 1.131 & 0.956 & 1.337 & Z Kolmogorov-Smirnov \\
\hline 0.200 & 0.108 & 0.320 & 0.056 & Significant level \\
\hline
\end{tabular}

Source: based on the research findings.

Where $\rho$ is the variables' relationship. If the significance of the test is less than 0.05 (meaningful level), the null hypothesis is rejected and the relationship between the variables is confirmed. (Iacobucci \& Duhachek, 2003).

\begin{tabular}{|c|c|c|c|c|}
\hline Process Structure & Knowledge Structure & Technology Structure & & \\
\hline 0.289 & 0.282 & 1 & Pearson Correlation & \multirow{3}{*}{ Technology Structure } \\
\hline 0.000 & 0.001 & & Significant Value & \\
\hline 114 & 114 & 114 & Number & \\
\hline 0.472 & 1 & 0.282 & Pearson Correlation & \multirow{3}{*}{ Knowledge Structure } \\
\hline 0.000 & & 0.001 & Significant Value & \\
\hline 114 & 114 & 114 & Number & \\
\hline 1 & 0.472 & 0.289 & Pearson Correlation & \multirow{3}{*}{ Process Structure } \\
\hline & 0.000 & 0.000 & Significant Value & \\
\hline 114 & 114 & 114 & Number & \\
\hline
\end{tabular}

Table 3. Relationship survey

Source: based on the research findings.

According to the results of the correlation table, the factors affecting the virtual implementation of $\mathrm{R} \& \mathrm{D}$ with a significant correlation test of less than 0.05 have a significant relationship. The sign of the correlation value indicates the direct or inverse relationship between the variables. For example, there is a significant positive relationship between the technology structure and the knowledge structure and the rate of this relationship is 0.282. (Iacobucci \& Duhachek, 2003).

To test the difference between $\mathrm{R} \& \mathrm{D}$ implementation among men and women, the mean comparison test is used in independent societies. To perform this test, the $t$ test is used and the following statistical test is performed.

$$
\begin{aligned}
& H_{\circ}: \mu_{1}=\mu_{2} \\
& H_{1}: \mu_{1} \neq \mu_{2}
\end{aligned}
$$

In which $\mu_{1}$ is the mean of dependent variables in men and $\mu_{2}$ is the mean of dependent variables in women. If the significance of the test is less than the significance level (0.05), then the null hypothesis is rejected, that is, the assumption of the equality of means is rejected in the two societies. In other words, the mean of dependent variable in men and women is significant and if the meaningful value of the test is greater than 0.05 means that there is no difference between the mean of the dependent variable in the two groups. In the mean comparison test, a significant value of more than 0.05 was found (0.605), which indicates that R \& D implementation is not influenced by gender. 
Table 4. Mean Comparison Test

\begin{tabular}{|c|c|c|c|c|c|c|c|c|c|c|}
\hline \multicolumn{7}{|c|}{ T-Test For Mean Comparison } & \multicolumn{2}{|c|}{$\begin{array}{c}\text { Levin Test for } \\
\text { Variance Equality }\end{array}$} & & \\
\hline \multicolumn{2}{|c|}{ Confidence Level Of $95 \%$} & \multirow{2}{*}{$\begin{array}{c}\text { Error } \\
\text { Difference }\end{array}$} & \multirow{2}{*}{$\begin{array}{c}\text { Mean } \\
\text { Difference }\end{array}$} & \multirow{2}{*}{$\begin{array}{l}\text { Signifi } \\
\text { cant } \\
\text { Level }\end{array}$} & \multirow{2}{*}{$\begin{array}{c}\text { Freedom } \\
\text { Degree }\end{array}$} & \multirow{2}{*}{$\begin{array}{c}\text { T- } \\
\text { Test }\end{array}$} & \multirow{2}{*}{$\begin{array}{c}\text { Signifi } \\
\text { cant } \\
\text { Level }\end{array}$} & \multirow{2}{*}{ F Statistic } & & \\
\hline High finite & Low finite & & & & & & & & & \\
\hline 0.21689 & -0.37093 & 0.14871 & -0.07702 & 0.605 & 146 & -0.518 & 0.454 & 0.564 & $\begin{array}{c}\text { Assuming } \\
\text { variance } \\
\text { equality }\end{array}$ & \multirow{2}{*}{$\begin{array}{c}\text { Impleme } \\
\text { ntation } \\
\text { of R \& D }\end{array}$} \\
\hline 0.20432 & -0.35836 & 0.13486 & -0.07702 & 0.574 & 19.969 & -0.571 & & & $\begin{array}{l}\text { Assuming } \\
\text { variance } \\
\text { inequality }\end{array}$ & \\
\hline
\end{tabular}

Source: based on the research findings.

Also, in the mean comparison test, the effect of marital status on R \& D implementation is significantly more than 0.05 , which indicates that $\mathrm{R} \& \mathrm{D}$ implementation is not affected by the marital status of individuals. In the next step, to analyze the effect of age on R \& D implementation, the variance analysis test is used. For this test, one-way ANOVA and F test statistic are used and the following statistical test is performed. (Iacobucci \& Duhachek, 2003).

$$
\begin{aligned}
& H_{\circ}: \mu_{1}=\mu_{2}=\ldots=\mu_{n} \\
& H_{1}: \mu_{1} \neq \mu_{2} \neq \ldots \neq \mu_{n}
\end{aligned}
$$

According to the test and the significance value of the test, we assume that null hypothesis is confirmed (significant value greater than 0.05 ) and the age of the individuals does not affect the implementation of R \& D. The variance analysis test is used to assess the effect of education on the implementation of $R \& D$. With regard to the test and the meaningfulness of the test, we conclude that null hypothesis is confirmed (a meaningful value of more than 0.05 ) and education does not affect the implementation of R \& D.

\subsection{Testing The Conceptual Model and Research Hypotheses}

Structural equations were used to test the conceptual model and research hypotheses.

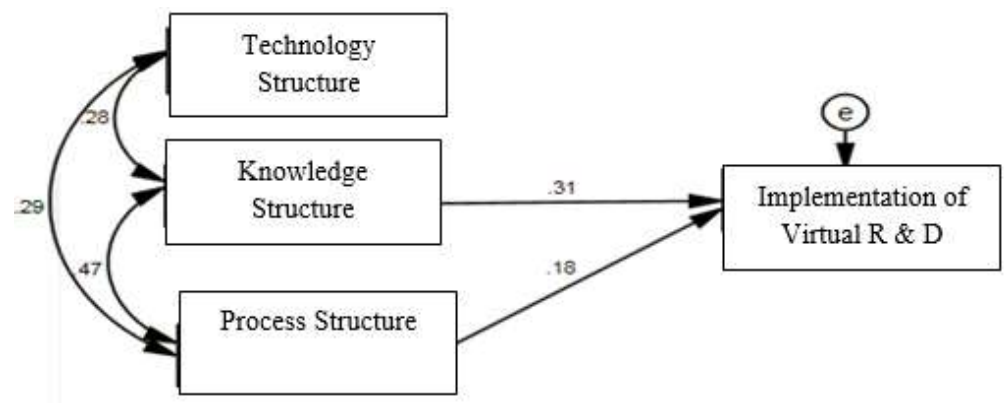

Figure 2. Conceptual Model of Software Output

Source: based on the research findings.

\subsection{Assessment of Model Fitness}

Each conceptual model deals with the question how is the extent with the reality? This key question is the subject of fitting the conceptual model of research. Table 5 shows a number of important indicators related to the assessment of the fit of the conceptual model of research.

Table 5. Fitness of Conceptual Modeling of Research

\begin{tabular}{|c|c|}
\hline Main Hypothesis & Indicators of Model Fitness \\
\hline 1 & Freedom Degree \\
\hline 1.251 & CMIN \\
\hline 1.251 & CMIN/DF \\
\hline 0.041 & RMSEA \\
\hline 0.996 & CFI \\
\hline 0.981 & NFI \\
\hline 0.889 & RFI \\
\hline 0.996 & IFI \\
\hline
\end{tabular}

Source: based on the research findings. 
The proposed model, which is based on the factor analysis performed on factors with an acceptable factor load in the confirmatory factor analysis, is a suitable model for investigating the relationship between the research variables, since, as shown in the table above, the value of the indicators of the adequacy of the model is above $80 \%$, which is excellent. In relation to the RMSEA, the values closer to zero are good fit and less than 0.05 to 0.1 represent a good fit of the model, which here is 0.041 , which makes good fit of the measurement model here. The RMSEA index shows that the performance of the residues in the model is relatively weak. (Iacobucci \& Duhachek, 2003).

\section{Conclusion}

According to the hypotheses, the following explanations are presented below. To test hypothesis 1 , since the probability value of significance is greater than 0.05 , the assumption of the equation of regression coefficient with zero $(B=0)$ is accepted against the assumption of the inequality of the regression coefficient with zero $(B \neq 0)$, which implies the rejection of the effect of the independent variable on the dependent variable. In other words, the technology structure in virtual teams does not directly affect the implementation of virtual $\mathrm{R}$ \& D. But through the knowledge structure of individuals and the process structure, it can influence the implementation of virtual R \& D; the effect of the technology structure on R \& D implementation through the structure of individuals is 0.09 and through the structure of the process is 0.05 . In order to examine hypothesis 2 , we need to consider the significance value in Table (5). Since this value is less than 0.05 , the assumption of the equation of regression coefficient with zero $(B=0)$ is rejected by the assumption of the inequality of the regression coefficient with zero $(B \neq 0)$, which confirms the effect of the independent variable on the dependent variable. According to the above table, the knowledge structure of individuals in virtual teams has a direct effect on the implementation of virtual $\mathrm{R} \& \mathrm{D}$, since its probability value is $95 \%$ less than 0.05 at the 95\% confidence level. The severity of the effect of the independent variable on the dependent variable is also determined in the table above from the standard estimation column, if this value is positive, the negative and negative effect has a negative effect. According to table 5, the knowledge structure of individuals in virtual teams has a positive effect on the virtual implementation of $\mathrm{R} \& \mathrm{D}$, since its probability value is $95 \%$ less than 0.05 at the $95 \%$ confidence level and the effect rate is 0.32 . In order to study hypothesis 3 , we need to consider the significance value in Table (5). Since this value is less than 0.05 , the assumption of the equation of the regression coefficient with zero $(B=0)$ is rejected by the assumption of the inequality of the coefficient of regression with zero $(B \neq 0)$, which confirms the effect of the independent variable on the dependent variable. According to the above table, the process structure in virtual teams has a direct effect on the virtual implementation of $\mathrm{R} \& \mathrm{D}$, since its probability value is $95 \%$ less than 0.05 at the $95 \%$ confidence level. The severity of the effect of the independent variable on the dependent variable is also determined in the table above from the standard estimation column, if this value is positive, the negative and negative effect has a negative effect. According to Table 5, the process structure in virtual teams has a positive effect on $\mathrm{R} \& \mathrm{D}$ implementation, since its probability value is $95 \%$ less than 0.05 at the $95 \%$ confidence level and the effect rate is (0.18) (Iacobucci \& Duhachek, 2003).

Table 6. Examining The Paths of the Model Based on Assumptions

\begin{tabular}{|c|c|c|c|c|c|c|}
\hline \multicolumn{2}{|c|}{} & $\begin{array}{c}\text { Standard } \\
\text { Estimation }\end{array}$ & S.E. & C.R. & $\begin{array}{c}\text { Significant } \\
\text { Probability Level }\end{array}$ \\
\hline $\begin{array}{c}\text { Implementation of Virtual } \\
\text { R \& D }\end{array}$ & $\leftarrow$ & $\begin{array}{c}\text { Individual } \\
\text { Knowledge } \\
\text { Structure }\end{array}$ & 0.315 & 0.131 & 3.500 & 0.000 \\
\hline $\begin{array}{c}\text { Implementation of Virtual } \\
\text { R \& D }\end{array}$ & $\leftarrow$ & Process Structure & 0.176 & 0.110 & 1.958 & 0.049 \\
\hline $\begin{array}{c}\text { Individual Knowledge } \\
\text { Structure }\end{array}$ & Process Structure & 0.472 & 0.016 & 5.178 & 0.000 \\
\hline Technology Structure & & Process Structure & 0.289 & 0.019 & 3.361 & 0.000 \\
\hline $\begin{array}{c}\text { Individual } \\
\text { Knowledge } \\
\text { Structure }\end{array}$ & 0.282 & 0.016 & 3.288 & 0.001 \\
\hline
\end{tabular}

Source: based on the research findings. 


\section{Limitations}

By reviewing both the responsible innovation and sustainability discourses, and presenting phenomenological evidence, we demonstrate that companies have adopted some aspects of RRI, even though it might not be recognised as such. Our findings indicate that these innovators recognise some of the ethical and societal concerns associated with their activities but their approach is often piecemeal; primary focus is upon the most immediate issues and on legal compliance, to the detriment of broader societal issues and wider challenges. We recommend explicit mechanisms that draw upon established ethical thought and practical academic work to improve companies' abilities to carry out their sustainability activities, and incorporate them into a responsible business strategy. We conclude with recommendations for innovators, corporate research and development, and policy.

\section{References}

1. Ale Ebrahim, N., Abdul Rashid, S. H., Ahmed, S., \& Taha, Z. (2011). The Effectiveness of Virtual R\&D Teams in SMEs: Experiences of Malaysian SMEs. Industrial Engineering and Management Systems, 10(2), 109-114. https://doi.org/10.7232/iems.2011.10.2.109.

2. Ale Ebrahim, N., Ahmed, S., \& Taha, Z. (2009a). Virtual R \& D teams in small and medium enterprises: A literature review. [Review]. Scientific Research and Essay, 4(13), 1575-1590. https://doi.org/10.5897/sre10.1005.

3. Ale Ebrahim, N., Ahmed, S., \& Taha, Z. (2009b, 11-12 May). Virtual R\&D Teams: Innovation and Technology Facilitator. Paper presented at the Engineering Education in 2025, School of Engineeri. https://doi.org/10.4018/9781599049014.ch011.

4. Ale Ebrahim, N., Ahmed, S., \& Taha, Z. (2010a). SMEs; Virtual research and development (R\&D) teams and new product development: A literature review. [Review]. International Journal of the Physical Sciences, 5(7), 916-930. https://doi.org/10.5897/sre10.1005.

5. Bagozzi, R. P., and Yi, Y. (1988). 'On the evaluation of structural equation models'. Journal of the Academy of Marketing Science, 16(1), 74-94. https://link.springer.com/article/10.1007/BF02723327

6. Badrinarayanan, V., \& Arnett, D. B. (2008). Effective virtual new product development teams: an integrated framework. [Conceptual paper]. Journal of Business \& Industrial Marketing, 23(4), 242-248. https://doi.org/10.1108/08858620810865816.

7. Bochenek, G., \& Ragusa, J. (2004). Improving Integrated Project Team Interaction Through Virtual (3D) $\begin{array}{lllll}\text { Collaboration. } & \text { Engineering }\end{array}$ https://doi.org/10.1080/10429247.2004.11415243.

8. Byrne, B. M. (2010). Structural equation modeling with AMOS: Basic concepts, applications, and programming (Second Edition ed.). New York: Taylor and Francis Group, LLC. https://doi.org/10.1080/15305051003637306.

9. Chen, H. H., Kang, Y. K., Xing, X., Lee, A. H. I., \& Tong, Y. (2008). Developing new products with knowledge management methods and process development management in a network. Computers in Industry, 59, 242-253. https://doi.org/10.1016/j.compind.2007.06.020.

10. Criscuolo, P. (2005). On the road again: Researcher mobility inside the R\&D network. Research Policy, 34, 1350-1365. https://doi.org/10.1016/j.respol.2005.05.018.

11. El-Tayeh, A., Gil, N., \& Freeman, J. (2008). A methodology to evaluate the usability of digital socialization in "virtual" engineering design. [Original Paper]. Research in Engineering Design, 19(1), 29-45. https://doi.org/10.1007/s00163-007-0037-7

12. Flores, M. (2006). Towards a Taxonomy for Networking Models For Innovation Network-Centric Collaboration and Supporting Frameworks (Vol. 224, pp. 55-66). Boston: Springer. https://doi.org/10.1007/978-0-387-38269-2_6

13. Gomez, J. O., \& Simpson, M. (2007). Achieving competitive advantage in the Mexican footwear industry. Benchmarking: An International Journal, 14(3), 289-305. doi/10.1108/14635770710753103/full/html

14. González, F. J. M., \& Palacios, T. M. B. (2002). The effect of new product development techniques on new product success in Spanish firms. Industrial Marketing Management, 31(3), 261-271. doi.org/10.1016/S0019-8501(00)00150-4

15. Hertel, G. T., Geister, S., \& Konradt, U. (2005). Managing virtual teams: A review of current empirical research. Human Resource Management Review, 15, 69-95. https://doi.org/10.1016/j.hrmr.2005.01.002

16. Huang, C.-C. (2009). Knowledge sharing and group cohesiveness on performance: An empirical study of technology R\&D teams in Taiwan. Technovation, 29(11), 786-797. https://doi.org/10.1016/j.technovation.2009.04.003 
17. Johnson, P., Heimann, V., \& O’Neill, K. (2001). The "wonderland" of virtual teams. Journal of Workplace Learning, 13(1), 24 - 30https://doi.org/10.1108/13665620110364745

18. Kirkman, B. L., Gibson, C. B., \& Shapiro, D. L. (2001). "Exporting" teams enhancing the implementation and effectiveness of work teams in global affiliates. Organizational Dynamics, 30(1), 12-29. https://doi.org/10.1108/13665620110364745

19. Laforet, S. (2008). Size, strategic, and market orientation affects on innovation. Journal of Business Research, 61(7), 753-764. https://doi.org/10.1016/j.jbusres.2007.08.002

20. Leenders, R. T. A. J., Engelen, J. M. L. V., \& Kratzer, J. (2003). Virtuality, communication, and new product team creativity: a social network perspective. Journal of Engineering and Technology Management, 20, 69-92. https://doi.org/10.1016/S0923-4748(03)00005-5

21. Lurey, J.S. and M.S. Raisinghani, An empirical study of best practices in virtual teams Information $\&$ Management, 2001. 38(8): p. 523-544. https://doi.org/10.1016/S0378-7206(01)00074-X

22. Iacobucci, D. and Duhachek, A. (2003). Advancing alpha: Measuring reliability with confidence. Journal of Consumer Psychology, 13(4), 478-487. https://doi.org/10.1207/S15327663JCP1304_14.

23. Martins, L. L., Gilson, L. L., \& Maynard, M. T. (2004). Virtual teams: What do we know and where do we go from here? Journal of Management, 30(6), 805-835. https://doi.org/10.1016/j.jm.2004.05.002.

24. May, A., Carter, C. (2001). A case study of virtual team working in the European automotive industry. Int. J. Industrial Ergonomics, 27, 171-186.

25. Paul, S., Seetharaman, P., Samarah, I., \& Peter Mykytyn, J. (2005). Understanding Conflict in Virtual Teams: An Experimental Investigation using Content Analysis. Paper presented at the 38th Hawaii International Conference on System Sciences, Hawaii. DOI: 10.1109/HICSS.2005.647.

26. Powell, A., G. Piccoli, and B. Ives (2004). Virtual teams: a review of current literature and directions for future research. The Data base for Advances in Information Systems, 35(1), 6-36. https://doi.org/10.1145/968464.968467.

27. Radas, S., Božić, Lj. (2009), The antecedents of SME innovativeness in an emerging transition economy, Technovation, 29, 438-450. https://doi.org/10.1016/j.technovation.2008.12.002.

28. Rust, F.C. (2015). Requirements for a systems-based research and development management process in transport infrastructure engineering. South African Journal of Industrial Engineering, 26(1), 87-101. https://doi.org/10.7166/26-1-904.

29. Shin, Y. (2005). Conflict Resolution in Virtual Teams. Organizational Dynamics, 34(4), $331-345$. https://doi.org/10.2189/asqu.51.3.451.

30. Singh, R. K., Garg, S. K., \& Deshmukh, S. G. (2008). Strategy development by SMEs for competitiveness: a review. [General review]. Benchmarking: An International Journal, 15(5), 525-547. https://doi/10.1108/IJQRM-05-2013-0088/full/html.

31. Stam, E. 2009. The roles of R\&D in new firm growth. Small Business Economy, 33, 77-89. https://doi.org/10.1007/s11187-009-9183-9.

32. Wagner, S. M., \& Hoegl, M. (2006). Involving suppliers in product development: Insights from R\&D directors and project managers. Industrial Marketing Management, 35, 936-943. https://doi.org/10.1016/j.indmarman.2005.10.009. 